Consumo digital. Engajamento. Imagem. Redes Sociais. 


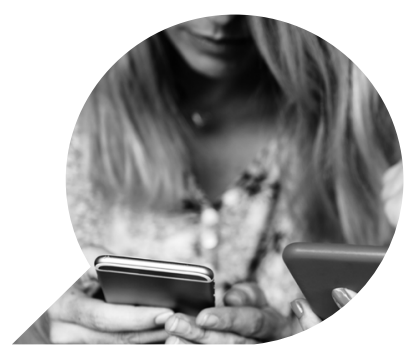

\title{
Tipos de conteúdo e engajamento: um estudo sobre o consumo de fanpages de casas noturnas LGBT
}

\author{
Types of Content and Engagement: a study on the \\ consumption of LGBT nightclubs fanpages
}

Tipos de Contenido y Compromiso: un estudio sobre fanpages de casas nocturnas LGBT

\begin{tabular}{c}
\hline HERTZ WENDEL DE CAMARGO $^{*}$ \\
\hline CLOVIS TEIXEIRA FILHO $^{\star *}$ \\
\hline MARCIA BOROSKI \\
\hline MARINA DE QUEIROZ SABBI \\
\hline
\end{tabular}

Resumo: A conexão ubíqua tem estimulado novas formas de consumo midiático, imersos no contexto de convergência. Soma-se a isso o cenário de consumo direcionado para nichos específicos, como o de Lésbicas, Gays, Bissexuais, Travestis, Transexuais e Transgêneros (LGBT). O presente artigo, a partir desse panorama,

\footnotetext{
* Doutor em Estudos da Linguagem (UEL). Professor do PPGCOM-UFPR. Líder do Grupo de Pesquisa ECCOS - Estudos sobre Comunicação, Consumo e Sociedade (UFPR).

** Mestre em Administração (UFPR). Professor dos cursos de Administração e Publicidade e Propaganda (UNINTER). Integrante do grupo ECCOS (UFPR).

*** Mestre em Comunicação (UEL). Professora dos cursos de Publicidade e Propaganda; e Jornalismo (UNINTER).

**** Graduanda de Comunicação Social - Publicidade e Propaganda (UNINTER).
} 
tem como objetivo analisar como os tipos de conteúdo midiático podem influenciar o engajamento em Fanpages das casas noturnas LGBT de Curitiba. Para isso, foi realizada uma pesquisa exploratória de casos múltiplos, utilizando também a análise de conteúdo. Como resultados destacam-se a presença de links e metasites como forma de divulgação, acompanhados de imagens e vídeos, que facilitam a compreensão, expressando a cultura visual. Além disso, observa-se que a adequação das diferentes mensagens à cultura vivenciada pelo público nas experiências fora da rede estão relacionadas ao engajamento.

Palavras-chave: Consumo digital; Engajamento; Imagem; Mídia; Redes Sociais.

Abstract: The ubiquitous connection has stimulated new forms of media consumption, immersed in the context of convergence. Besides that, the consumption scenario directed to specific niches, such as Lesbian, Gay, Bisexual, Transvestite, Transsexual and Transgender (LGBT) has been transformed by the internet. This article, based on this panorama, aims to analyze how the media content types can influence the engagement in Fanpages of the LGBT ballads of Curitiba. For this, an exploratory study of multiple cases was carried out, also using content analysis. As a result, are highlighted the presence of links and metasites as a form of dissemination, accompanied by images and videos, facilitate understanding and expressing the visual culture. Besides that, it is observed that the adequacy of the messages to the experiences outside the network are related to the engagement.

Key words: Digital consumption; Engagement; Image; Media; Social Networks.

Resumen: La conexión ubicua ha estimulado nuevas formas de consumo de medios, inmersos en el contexto de la convergencia. Además, el consumo dirigido a grupos específicos tales como los destinados a las lesbianas, gays, bisexuales, travestis, transexuales y transgéneros (LGBT) se ha transformado por medio de las posibilidades de la red. Este estudio tiene como objetivo examinar cómo los tipos de contenido de los medios de comunicación pueden influir en lo compromiso en fanpages de casas nocturnas LGBT en la ciudad de Curitiba. La metodología se concentra en una investigación de varios casos, mediante el análisis de contenido. Como resultado, se destacan la presencia de 
links y metasites como una forma de divulgación, acompañado de imágenes y vídeos, que facilitan la comprensión, expresando la cultura visual. Además, se observó que los contenidos de más grande compromiso hacen la adecuación de los diversos mensajes a la cultura vivenciada por el público fuera de la red.

Palabras clave: Consumo digital; Compromiso; Meios de Comunicaión; Imagen, Redes Sociales. 


\section{Introdução}

O uso de tecnologias digitais de informação e comunicação (TDIC) de forma intensa proporcionou maior interação comunicacional, que segundo Morigi e Pavan (2004, p. 120) "fez com que a sociabilidade entre os atores envolvidos se modificasse substancialmente". O maior acesso à informação em rede resulta na interação entre enunciador e enunciatário, em um contexto de produção de conteúdo pelos usuários. Essa característica de consumo e produção concomitante, chamada de prosumer, tem sido avaliada como um dos principais fatores que moldam a cultura da conexão (JENKINS; GREEN; FORD, 2014). Soma-se a essa questão a colaboração associativa entre clientes de uma marca em ambiente híbrido, isto é, dividindo a conexão constante com as interações offline (JENKINS, 2008).

A cultura da convergência é um dos fatores que influenciam a mudança do consumo midiático, dando poder aos clientes. Ela é entendida como a mudança proporcionada pela internet, e ampliada por meio do desejo do consumidor, na produção, veiculação e consumo de comunicação em que mídias são direcionadas para um mesmo local e tempo, convenientes ao enunciatário (JENKINS, 2008). Dessa forma, pesquisadores do consumo material e midiático possuem o desafio de interpretar o ambiente em rede, que altera o comportamento dos agentes envolvidos nesse processo. Nesse sentido, a pesquisa realizada pela PWC (2017), levantou que $77 \%$ dos usuários brasileiros usam as redes sociais como fator decisivo na hora de finalizar a ação de compra e consumo de serviços.

A partir das táticas de comunicação online as organizações podem incentivar a resposta de clientes. O estudo publicado pelo Google Advertising Age no Content Marketing Institute (2014) aponta que 84,1\% das marcas já estão direcionadas aos seus clientes de forma com que incentivem a participação no ambiente digital. A partir desse contexto é que se amplia a relevância de mensurar o chamado engajamento, assim como seus fatores antecedentes e consequentes. Segundo Haven (2007, p. 5) "engajamento é o nível de envolvimento, interação, intimidade e influência que um indivíduo tem com uma marca ao longo do tempo".

Como elemento consequente do engajamento Maddox (2014) relata uma relação direta e positiva com a lealdade à marca, podendo se estender também ao relacionamento offline. Já O’Brien e Toms (2008) evidenciam as experiências sensoriais, a customização da informação e dos formatos de conteúdo oferecidos no contexto digital como antece- 
dentes. Uma vez que o engajamento positivo pode ampliar o desempenho organizacional e os elementos que fomentam esse comportamento podem ser influenciados pela organização, estudar os diferentes tipos de conteúdo digital torna-se relevante.

Outra oportunidade apresentada às organizações por meio das redes é a possibilidade de gerar informação e conhecimento. Um dos segmentos que tem sido foco de novos produtos é o LGBT (Lésbicas, Gays, Bissexuais, Travestis, Transexuais e Transgêneros). No Brasil, o potencial financeiro do segmento LGBT é estimado em US\$ 133 bilhões, o equivalente a R \$ 418,9 bilhões, ou 10\% do produto interno bruto nacional, segundo a Out Leadership (2015). Ainda segundo o estudo, o consumo LBGT, quando comparado ao público heterossexual, mostra-se maior nas atividades hedônicas como entretenimento e viagens.

Diante do cenário apresentado, o presente estudo tem como objetivo analisar como os tipos de conteúdo midiático podem influenciar o engajamento digital em Fanpages de casas noturnas do segmento LGBT na cidade de Curitiba. Para isso, foi realizada uma pesquisa exploratória por meio de estudo de casos múltiplos. Como contribuições desta pesquisa destacam-se a caracterização dos tipos de comunicação digital, o desenvolvimento da avaliação do engajamento, a relação entre tipos de conteúdo de comunicação e o comportamento ativo do consumidor, além da possibilidade de gestão de conteúdos para ampliar o desempenho nas organizações em conjunto com os demais esforços de marketing.

\section{Cultura da Convergência e a Comunicação Integrada de Marketing}

A cultura da convergência é sustentada em três pilares: a convergência tecnológica dos meios de comunicação, a cultura participativa e a inteligência coletiva, caracterizando "um novo paradigma de comunicação entre os sujeitos, interativo, dialógico, imprevisível e surpreendente"(ARAÚJO, 2014, p.3). Diante da tecnologia, participação (co-criação) e do conhecimento coletivo, a convergência modifica a indústria cultural e as relações com o público.

As mudanças encontradas no ambiente digital afetam também o comportamento offline, pois consumidores se encontram em cenários híbridos, em que a conexão por longos períodos é compartilhada com vivências fora das redes. Segundo Beiguelman (2004) em um ambiente híbrido se reconfigura a identidade entre conteúdo e suporte, liberando 
o polo emissor (participação ativa do receptor). Essa conjectura, altera igualmente aspectos relacionados às representações culturais e à forma como as organizações se comunicam com seus públicos, devido ao macroambiente em rede (HALL, 1998; CASTELLS, 1999). Portanto, organizações orientadas ao mercado devem se preocupar com o ambiente digital não apenas pela possibilidade de consumo nas redes, mas também pela mudança de comportamento que ele provoca no consumo offline.

As redes sociais dão poder ao cliente para julgar e fazer parte da marca. Segundo Lemos (2008), no ciberespaço, cada sujeito é um potencial produtor de informações, capaz de atuar como influenciador. As associações feitas por usuários são delimitadas também pelo que os outros fizeram (LATOUR, 2012). Segundo o autor, essa conjectura abriu espaço para convergências temporárias, sendo que, a maneira mais adequada de saber o que está sendo consumido é observando de forma livre os componentes dentro da rede. As marcas nas redes sociais utilizam o espaço para promoções e divulgações, que ganham força dos consumidores por meio do engajamento.

Com o advento da integração online, a produção de conteúdo facilita a comparação e decisão do consumidor. Sobre isso, Kendzerski (2009) diz que o acesso à informação dá poder para o consumidor opinar. Segundo Mattos (2009), para as marcas terem uma participação ativa na rede é necessário interagir e conhecer seu público, além de ter um panorama que possibilite antecipar as tendências do mercado. Os dados da Pesquisa Brasileira de Mídia (SECOM, 2015), reforçam as possibilidades das plataformas digitais para as organizações. Segundo ela, entre os internautas, $92 \%$ estão conectados por meio de redes sociais, sendo a mais utilizada o Facebook (83\%). Em 2009, o Brasil reunia 30 milhões de pessoas todo mês nas redes, somando $1,3 \mathrm{mi}$ lhões de usuários no total, tendo uma média de 2 milhões de eventos mensais (NANNI; CAÑETE, 2010).

\section{Tipos de Conteúdo nas Redes Sociais e Engajamento Digital}

A participação ativa do consumidor por meio do digital expõe a importância de mensurar o engajamento. Segundo Van Doorn et al. (2010, p. 254) engajamento é a "[...]manifestação de comportamento dos clientes em direção a uma marca ou empresa, que vai além da compra, resultando em condutores motivacionais". Essa definição é utilizada também pelo Marketing Science Institute (MSI). 
Para as organizações envolvidas em serviços, as táticas relacionais de comunicação, como as redes sociais tornam-se ainda mais relevantes. Segundo Lovelock e Wirtz (2006) a satisfação está diretamente ligada à retenção, em um cenário em que organizações de serviços têm o desafio de ponderar as expectativas de clientes, uma vez que atuam por meio de produtos intangíveis. No que tange à gestão do engajamento, Haven (2007) classificou níveis que direcionam sua mensuração, sendo eles: envolvimento e interesse no tema, a interação no assunto, a intimidade com o tema ou marca e a influência ao recomendar a marca.

Do ponto de vista da comunicação publicitária, autores como Figueiredo (2005) e Carrascoza (2004) propõem classificações para os tipos de mensagem. Para Figueiredo, os tipos de anúncio podem ser classificados em hard sell, soft sell, oportunidade, teaser, informe publicitário, comunicado e institucional. Já para Carrascoza as formas trabalhadas em textos publicitários podem ser apolíneas ou dionisíacas. Embora não sejam especificamente relacionadas ao ambiente digital, as classificações podem ser consideradas uma vez que as fanpages estão atreladas à divulgação publicitária das organizações.

O formato do conteúdo no Facebook é proposto pela própria plataforma, pelos algoritmos e métricas apresentadas no Facebook Analitics. Antonello (2016) classifica os conteúdos em vídeo, vídeo compartilhado de outra página, links, fotos e publicações em texto. Essa classificação é semelhante à proposta da SECOM (2016), que divide os tipos de conteúdo em quatro quadrantes pela complexidade e característica que guiam o usuário pela navegação, sendo eles: vídeo ou videográficos; metasites ou hotsites; texto puro; imagens ou infográficos.

Tendo como base as classificações apresentadas, o cenário do Facebook, assim como de outras redes sociais, é repleto de manifestações imagéticas, sejam fotografias, artes, imagens em movimentos, cuja produção segue expressões já consolidadas (fotografia), mas também se apresenta como criadora (memes e gifs). Nesse sentido, as imagens, na sua diversidade, acabam sendo relevantes para compreender o engajamento.

De acordo com Malena Contrera (2002), o relacionamento do homem com imagens é de data muito anterior ao aparecimento dos meios de comunicação digitais. As primeiras imagens criadas pelo homem remetiam ao sagrado: elas eram uma forma de vínculo ou encontro com aquilo que o indivíduo cultuava (CONTRERA, 2002). Atualmente, percebemos também funções informativas e estéticas, as quais podem ser compreendidas pelo caráter mágico defendido por Vilém Flusser (1985). 
"Imagens são códigos que traduzem eventos em situações, processos em cenas. Não que as imagens eternizem eventos; elas substituem eventos por cenas" (FLUSSER, 1985, p. 7). O autor compreende que a produção de imagens técnicas (aquelas produzidas por aparelhos, como a fotografia, o audiovisual, as imagens produzidas por softwares) dispara uma relação entre o humano e o aparelho, cuja metáfora é a Caixa preta: um sistema de produção, circulação e consumo com possiblidades pré-programadas, processos de subversão e reprogramação.

O homem, então, não veria as imagens como uma forma de representar o mundo, mas sim como única janela possível (FLUSSER, 1985; CONTRERA, 2002). As imagens não são uma representação automática do real, mas um recorte, selecionado intencionalmente e cuja busca pelo padrão é motivada pela necessidade de vínculo com o objeto ou símbolo, representando o poder dos mitos (CONTRERA, 2002). Sendo a sociedade governada por imagens, tal como propõe Baitello Junior (2005), ocorre o processo denominado de Iconofagia: o consumo de imagens pelo homem e o consumo do homem pelas imagens.

\section{Metodologia}

A partir do objetivo estabelecido nesta pesquisa foi realizado um estudo de caso múltiplo. Essa metodologia possibilita análises em diferentes contextos e contribui para pesquisas que sugiram modelos teóricos possíveis de validação futura. Os casos são adicionados gradualmente à pesquisa, até que haja uma "saturação teórica" (GIL, 2002). Dessa forma, um mesmo objeto de estudo é avaliado em diferentes casos com o intuito de identificar os elementos que podem influenciar um fenômeno e entender como essa relação ocorre.

O corpus de estudo foi definido por meio do tempo de vida das organizações, histórico de comunicação em redes sociais e a localização na cidade de Curitiba. A seleção ocorreu com organizações com mais de 2 anos no mercado e mínimo de 2 anos de comunicação por meio do Facebook, sendo elas: o Bar do Simão, V.U, James e Soviet. As divulgações dos serviços oferecidos são feitas através das páginas oficiais no Facebook. O uso dessa rede social se justifica ao observar a Pesquisa Brasileira de Mídia. O Brasil teve um grande crescimento no uso de mídias sociais. $92 \%$ dos internautas mantêm perfis em redes sociais, sendo o Facebook a mais utilizada (83\%). 
Esta pesquisa foi dividida em três etapas e a coleta foi realizada durante todo o mês de abril de 2017. A primeira etapa refere-se à classificação dos conteúdos postados nas fanpages. Para analisar esses conteúdos foram utilizadas as classificações propostas por SECOM (2016) e Antonello (2016). A segunda etapa teve como foco a mensuração do engajamento. Para essa análise foram mensuradas as quantidades de curtidas, comentários e compartilhamentos, conforme sugestão de Antonello (2016). Assim, cada um dos casos terá o conteúdo classificado em vídeo, vídeo compartilhado, imagem, link e texto, além da avaliação do engajamento. $\mathrm{O}$ engajamento entre as fanpages ainda foi comparado por meio de um score, a partir da fórmula do Facebook que mede a taxa de engajamento de um post (Figura1).

Figura 1 - Mensuração da Taxa de Engajamento

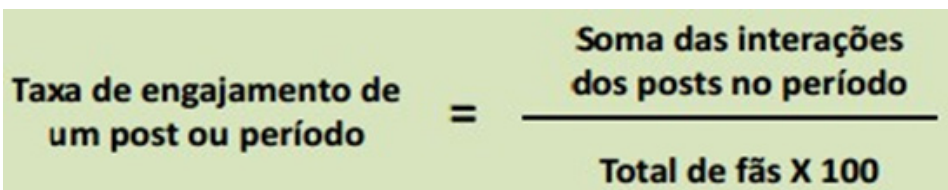

Fonte: FSB Digital

A influência de cada canal para interação e alcance com os clientes foi comparada, sabendo quantas pessoas são fãs da página e como interagem. O engajamento foi mensurado por meio de coleta manual e sem acesso às métricas das páginas. Assim, foram calculados os posts com maior número de reações, compartilhamentos e comentários, divididos pela quantidade de curtidas da página.

A terceira etapa refere-se à análise de conteúdo das mensagens que obtiveram o maior engajamento em cada um dos casos. A avaliação ocorreu por meio da análise de conteúdo proposta por Bardin (2009). A partir dessa metodologia, os resultados foram apresentados seguindo as etapas citadas. Para a análise dos conteúdos postados foram contatados os administradores das páginas que relataram não ter utilizado impulsionamento para a divulgação das mensagens durante o período da pesquisa.

\section{Resultados e Discussão}

A partir das publicações coletadas na Fanpages das casas noturnas de Curitiba, foi observado que a divulgação dos serviços e festas é a prin- 
cipal mensagem. Para cada festa (cada dia da semana que a casa abre) é sugerido um evento próprio no Facebook, vinculado com a página da organização. Diante disso, a utilização dos links dos eventos nos conteúdos divulgados caracteriza um metasite, segundo a SECOM (2015).

Para caracterizar os tipos de conteúdo, os metasites foram subdivididos em duas categorias, sendo elas: metasites diretos, que direcionam aos espaços dos eventos e metasites compartilhados, que levam a uma estrutura de navegação diferente. Por outro lado, utilizando a proposta da Antonello (2016), os links são incorporados ao tipo de conteúdo, analisando assim, o formato de destaque das publicações. Serão contabilizados como link somente aqueles que levarem à uma estrutura de navegação diferente do site de partida, subentendendo os links internos para analisar o tipo de conteúdo. A Figura 2 resume as etapas iniciais da pesquisa.

É possível observar que o Bar do Simão divulga seus eventos através de links diretos, tem a predominância no uso de imagens, infográficos e conteúdos ilustrados, exibindo seus serviços. Porém esses conteúdos não convertem efetivamente ao engajamento. Já no V.U os eventos são divulgados por meio de imagens diretamente na página e suas promoções convidam o usuário para uma reação ao conteúdo postado. No James é usado link para os eventos e imagens para as publicações, com uma dinâmica de conteúdos as imagens geram visualização e o engajamento se dá por meio dos links. O Soviet divulga seus eventos por links diretos e predomina o uso de imagens para seus conteúdos, porém não possui alta taxa de engajamento, uma vez que, pelo uso de links, a página oficial torne-se um pouco obsoleta e com pouca colaboração do usuário, sendo utilizada para posicionamento de marca, mas sem interação dos clientes. 
Figura 2 - Infográfico dos Resultados de Conteúdos e Engajamento

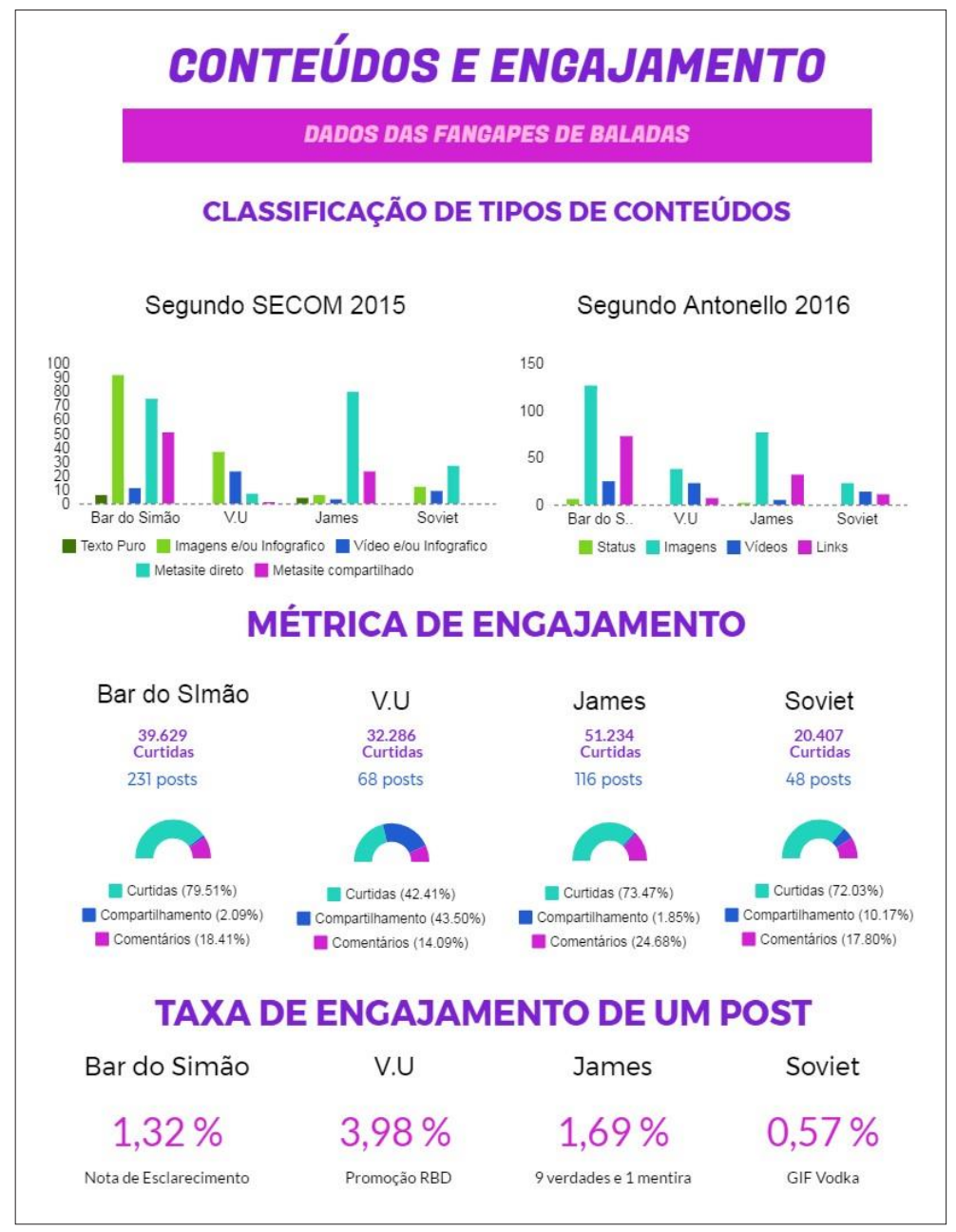

Fonte: Os autores

A partir dos dados apresentados, é possível verificar que os elementos visuais predominam nas publicações dos quatros estabelecimentos. Muitas vezes a imagem ilustra a publicação por links/metasites diretos. Verifica-se assim o fortalecimento da relação entre homem-imagem e a consciência desta relação na produção e conteúdos para redes sociais. Relação que se mantém pelo caráter mágico das imagens (FLUSSER, 1985), ou seja, pela potência que imagens têm de traduzir cenas, recriando momentos de referências visuais, e pela relação de culto e pelas 
produções de sentido por meio do mito, muitas vezes (CONTRETA, 2002 e CONTRERA, 2010), presente desde os primórdios da história do homem. A consolidação, a penetração e onipresença das imagens nesses posts fazem referência e corroboram com o que aponta Baitello Jr. (2005) sobre a relação da sociedade com cultura visual. Ela perpassa a produção, a circulação e o consumo de bens simbólicos, caracterizando a predominância que dos tipos de conteúdos sejam visuais. Observa-se ainda que os tipos de conteúdo são utilizados simultaneamente, mesclando os formatos para complementar a mensagem.

De acordo com Haven (2007) o envolvimento com a marca por meio das curtidas na página se dá ao sentimento de pertencimento que o cliente possui com a marca, a associação pessoal que o internauta constrói com a formação do posicionamento da página. A interação medida por post, é estabelecida a partir do conteúdo que remete em primeira instancia a reafirmação dos valores da marca, junto com o reconhecimento pessoal no conteúdo do comportamento do cliente.

Com um fluxo de postagens diferente entre as páginas é possível observar que a quantidade de publicações e likes são variáveis que compõe o engajamento. Porém, é a interação do cliente que determina esse fenômeno. Podemos observar que o Bar do Simão tem uma quantidade maior de posts, mas um baixo nível de engajamento, uma vez que a maior interação do público com o conteúdo é em forma de curtida/ reação, sem acarretar maior envolvimento e repercussão do conteúdo. Por outro lado, o V.U tem uma quantidade menor de post, mas uma interação maior do cliente, contemplando as três formas de envolvimento, o que leva ao maior engajamento.

No caso do James, a quantidade de likes da página é a variável mais relevante, pois não tem uma interação completa, porém possui um bom engajamento pela quantidade elevada de reações/curtidas. Com a predominância de metasites ao dividir o uso de links observamos a utilização de imagens e elementos visuais são utilizados para expor de forma ilustrativa informações e fatos. O interessante é que, com essa linha de comunicação o post que obteve maior engajamento é um tipo de conteúdo apresentado em texto puro/status, que demonstra a necessidade de qualidade no conteúdo engajado. Com uma discrepância de quantidade e interação em relação as outras páginas, o Soviet teve um post mais engajado que não faz relação com a balada, e, sim, com o hábito de consumo, trazendo em evidência a convergência cultural. 
Segundo Haven (2007) o engajamento monitora as ações do consumidor, além da transação. Ou seja, as utilizações do engajamento em conjunto com a conversão estão ligadas ao conteúdo de qualidade, levando em conta os objetivos e elementos utilizados para saber qual interesse do público nos assuntos da internet. Seguindo a análise de conteúdo proposta por Bardin (2009), as mensagens com maior engajamento de cada organização foram categorizadas pelo tipo de conteúdo de rede social utilizado, tipo de anúncio publicitário (FIGUEIREDO, 2005) e também em textos apolíneos ou dionisíacos (CARRASCOZA, 2004).

Tabela 1 - Análise dos Conteúdos com Maior Engajamento

\begin{tabular}{llll}
\hline & Tipo de Conteúdo & Tipo de Anúncio & Texto Publicitário \\
\hline Bar do Simão & Imagem & Comunicado & Apolíneo \\
V.U & Imagem & Hard Sell & Apolíneo \\
Jame & Texto Puro & Oportunidade & Dionisíaco \\
Soviet & Vídeo & Soft Sell & Dionisíaco \\
\hline
\end{tabular}

Fonte: Elaborado pelos autores

A publicação do Bar do Simão (Figura 3) teve seu conteúdo decupado. O post é do dia 1 de abril de 2017, em formato de imagem, acompanhado de texto, compondo um post com vários tipos de conteúdo. Em um primeiro momento, a imagem analisada apresenta o aspecto amassado e com líquido derramado sobre a as cores da bandeira LGBT. $\mathrm{O}$ texto fala sobre um incidente ocorrido no estabelecimento sobre a intolerância aos homossexuais.

O segundo aspecto nos leva a pensar na preocupação da marca com a comunidade LGBT o posicionamento da marca sobre essas questões torna-se visível no uso do símbolo da marca na imagem. Sobre as associações positivas e negativas feitas a partir dos acontecimentos na balada e declarações feitas por clientes envolvidos, acompanhado do título como terceiro aspecto, sem detalhes, que obriga o usuário a ler/interpretar o texto para saber do que se trata. Trazendo o enunciado de "esclarecimento" remete à retratação da imagem indesejada ligada à empresa. 
Figura 3 - Publicação com maior engajamento do Bar do Simão

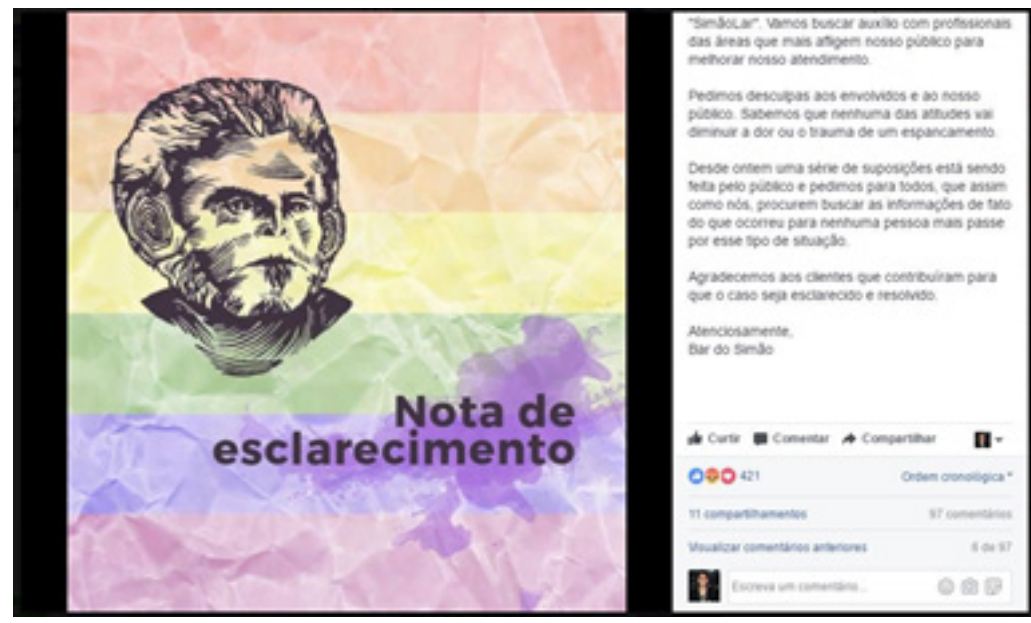

Fonte: Print da Fanpage do Bar do Simão

Figura 4 - Publicação com maior engajamento do V.U

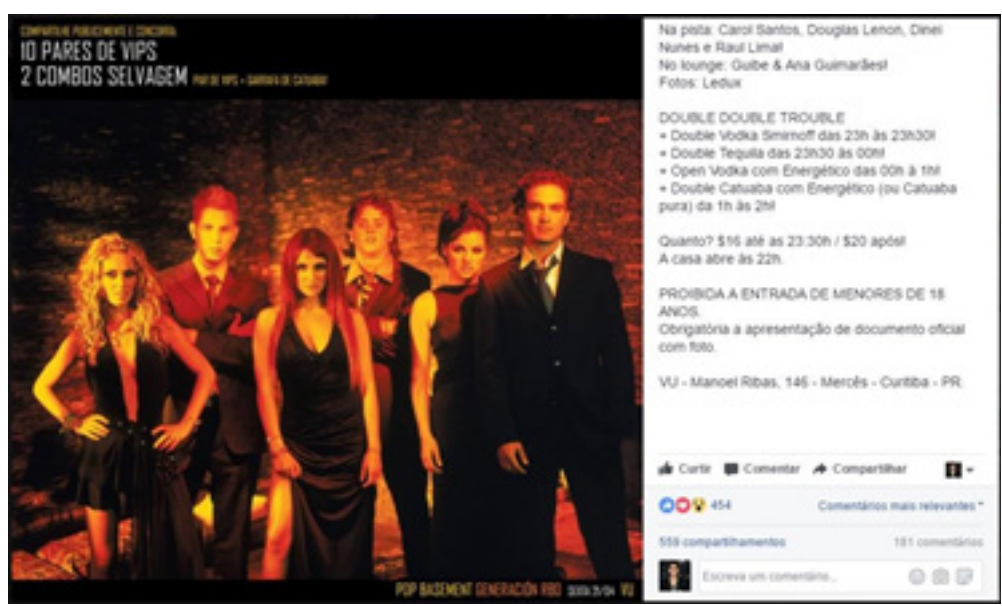

Fonte: Print da Fanpage do V.U 
Figura 5 - Publicação com maior engajamento do James

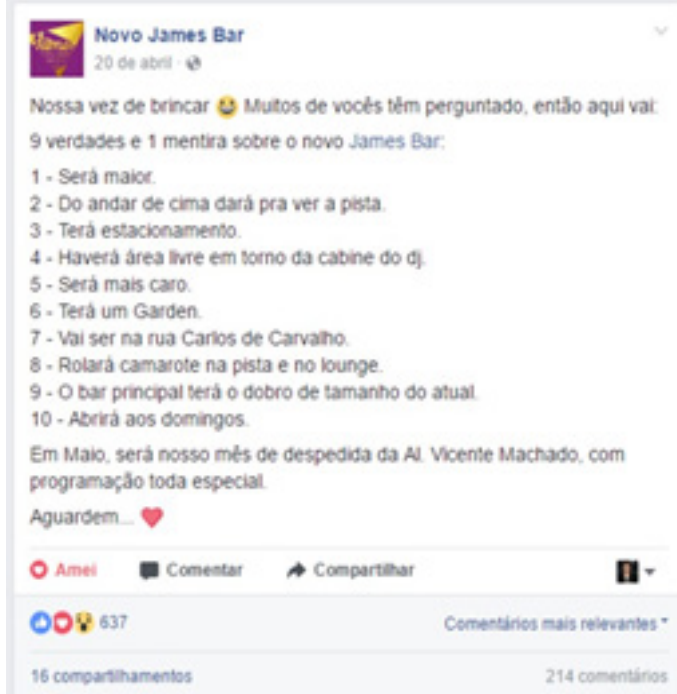

Fonte: Print da Fanpage do James

Figura 6 - Publicação com maior engajamento do Soviet

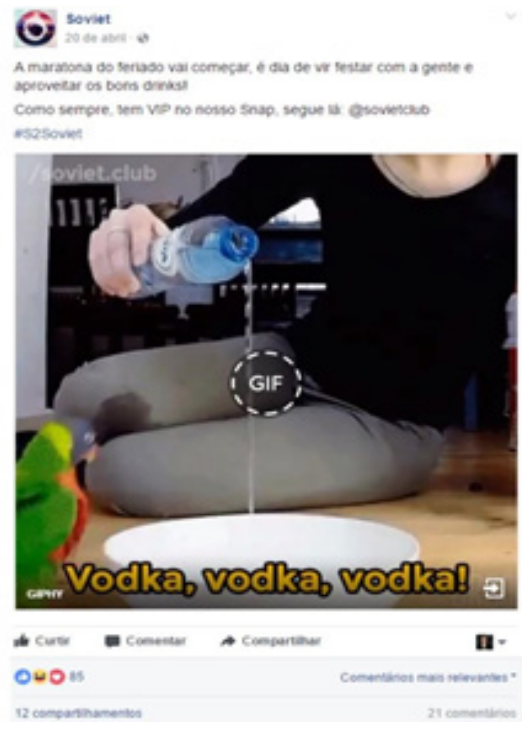

Fonte: Print da Fanpage do Soviet 
A postagem mais engajada do V.U (Figura 4) traz seu conteúdo em formato de imagem, utilizada para promoção de uma festa temática promovida pelo bar. Postada no dia 17 de abril de 2017, o conteúdo traz a imagem do tema da festa, a banda RBD, junto com enunciado com as informações do acontecimento, horário, preço, promoções. A mensagem é acompanhado por um texto descritivo das informações pertinentes sobre o evento em questão.

A imagem estampa a capa de um CD da banda e as informações estão dispostas na página seguindo a linha de leitura diagonal da esquerda superior até a direita inferior. $\mathrm{O}$ texto em branco e cores quentes (amarelo e laranja) relaciona-se as cores da imagem utilizada, a disposição tem as promoções em um primeiro momento, chamando atenção do púbico e a baixo, lembrando uma nota de rodapé as informações com o nome da festa, data e horário. Assim, é possível observar a preocupação com a estética da imagem e a associação imediata feito pelo cliente com a imagem, relacionando-a com referências pessoas e nostálgicas que a banda possibilita.

A publicação engajada do James (Figura 5) foi publicada em 20 de abril, tem seu conteúdo exposto em formato de status ou texto puro, a qual utiliza uma brincadeira de corrente para divulgar a nova estrutura da casa. O texto tem o convite à interação por parte do cliente, o que alavanca o engajamento no post, onde o usuário deve acertar qual afirmativa é falsa. A brincadeira textual tem 10 afirmativas positivas com relação a marca e ao estabelecimento, porém uma delas é falsa. No fim da mensagem a marca utiliza a expressão "aguardem" prometendo informações concretas sobre o novo local. Diante disso, a utilização de texto corresponde às expectativas da mensagem, passando ao público as vantagens e benefícios do estabelecimento, de forma descontraída e sem ser presunçoso.

A publicação do Soviet (Figura 6) que teve maior engajamento foi postada no dia 20 de abril de 2017, em formato de GIF que corresponde a um tipo de vídeo ou infográfico animado. O recorte de vídeo é utilizado para ilustrar de forma cômica o consumo vodka, fazendo referência a bebida por meio das palavras utilizadas como legenda na imagem, porém de forma irônica a bebida que está sendo derramada é agua. A ave que rodeia o prato com o liquido é a representação do consumidor, associada ao status que acompanha o formato, o enunciado convida ao consumo de "bons drinks" e frequência nas festas da marca. Assim, o 
formato escolhido pelo Soviet tem ampla interpretação, não tendo um objetivo especifico bem delimitado.

Os resultados analisados mostram que as mensagens mais engajadas não pertencem ao mesmo tipo de conteúdo, mesmo tratando do mesmo segmento de serviço. Ou seja, os casos não expõem um padrão de formato para alcançar e engajar o cliente. Os conteúdos que obtiveram maior engajamento nas páginas das casas noturnas LGBT de Curitiba mostram que conhecer o ambiente em que o conteúdo será inserido é relevante para o planejamento de mensagens. $\mathrm{O}$ envolvimento com o ambiente offline torna possível o engajamento digital, de forma que a associação do conteúdo das Fanpages busca coesão exofórica à rede, que emergem da cultura LGBT.

\section{Considerações finais}

A análise dos dados evidencia que diferentes tipos de conteúdo podem gerar engajamento, sem um detalhamento no padrão de publicação que leve a esse resultado. No entanto, há preferência por imagens e vídeos nas publicações, reiterando os aspectos da cultura visual, reiterando a preferência e necessidade de representações imagéticas nos produtos culturais (CONTRERA, 2002 e BAITELLO, 2005). Dessa forma, o espaço híbrido apresenta desafios à comunicação, uma vez que o engajamento parece estar relacionado ao envolvimento de questões ocorridas também fora da rede.

Como direcionamentos, observa-se o uso predominante de links e metasites para divulgar a organização, que é articulada de forma mais positiva para o engajamento com imagens ou vídeos. Outro ponto relevante é que a quantidade de seguidores não gera a interação de forma autônoma, sendo necessário estimular a participação em rede, ainda que o tipo de conteúdo não seja suficiente como explicação exclusiva do engajamento. Nesse sentido, as métricas de engajamento apontaram a importância não apenas dos níveis de interação e envolvimento, mas principalmente nos níveis de intimidade e influência, expostos por Haven (2007).

Diante das limitações da pesquisa e resultados obtidos, sugere-se que as classificações possibilitadas pela metodologia sejam replicadas em outros segmentos. Além disso, estudos longitudinais, com um período maior de tempo, em um mesmo segmento, podem ser consideradas para a verificação de padrões relacionados entre conteúdos e engaja- 
mento digital. A comparação entre redes sociais distintas também deve ser considerada uma vez que podem auxiliar o desenvolvimento prático e teórico do tema.

\section{REFERÊNCIAS}

ANTONELLO, Taynara. Social Media Já: Descomplique e produza conteúdo online. Curitiba:

BAITELLO JUNIOR, Norval. A era da iconofagia. Ensaios de comunicação e cultura. São Paulo: Hacker Editores, 2005.

BARDIN, L. Análise de Conteúdo. Lisboa, Portugal; Edições 70, LDA, 2009.

BEIGUELMAN, Giselle. Admirável mundo cíbrido. Disponível em: <https://www. academia.edu/3003787/Admir\%C3\%A1vel_mundo_c\%C3\%ADbrido>. Acesso em: $18 / 05 / 2017$.

CAÑETE, Karla. NANNI, Henrique. A Importância das Redes Sociais como Vantagem Competitiva nos Negócios Corporativos. Convibra Administração, São Paulo, 2010. n.15. Disponível em: <http://www.convibra.com.br/upload/paper/adm/ adm_982.pdf $>$. Acesso em: 29/03/2017.

CARRASCOZA, J. A. Razão e sensibilidade no texto publicitário. São Paulo: Futura, 2004.

CASTELLS, Manuel. A sociedade em rede. São Paulo: Paz e Terra, 1999.

CENSO GLS. Instituto de Pesquisa e Cultura GLS. IFD comunicação. ed. 2. 2008. Disponível em: <http://www.ifd.com.br/publicidade-e-propaganda/quem-e-opublico-gls/>. Acesso em 20/05/2017.

COMPORTAMENTO DE ENGAJAMENTO DE CLIENTES: Fundamentos Teóricos e Direções de Pesquisa. Diário de Pesquisa de Serviços. 13 (3), 253-266.

CONTRERA, Malena S. Mídia e pânico. São Paulo: Annablume, 2002.

CONTRERA, Malena Segura. Mediosfera: meios, imaginário e desencantamento. São Paulo: Annablume, 2010.

FIGUEIREDO, Celso. Redação publicitária: sedução pela palavra. São Paulo: Ed. Pioneira Thomson Learning, 2005.

FLUSSER, Vilém. A filosofia da caixa preta: ensaios para uma futura filosofia da fotografia. Rio de Janeiro: Relume-Dumará, 1985. 
FSB-Digital. Normatização de Métricas. Disponível em: <http://intranet.fsb.com.br/ intranet/wpcontent/uploads/2013/04/3.-Taxa-de-engajamento-NormatizaCACAode-MCAtricas.pdf>. Acesso em 10/06/2017

GIL, Antônio Carlos. Como elaborar projetos de pesquisa. 4. ed. São Paulo. Atlas, 2002.

HALL, S. A identidade cultural na pós-modernidade. 2. ed. Rio de Janeiro: DP\&A, 1998.

HAVEN, Brian. Marketing's new key metric: engagement. Forrester Research, 2007.

JENKINS, Henry. Análise documental como método e como técnica. Trad. ALEXANDRIA, Susana. Cultura da convergência. São Paulo: Aleph, 2008.

JENKINS, Henry; GREEN, Joshua; FORD, Sam. Cultura da Conexão: criando valor e significado por meio da mídia propagável. São Paulo: Aleph, 2014.

KENDZERSKI, Paulo Roberto. Web Marketing e Comunicação Digital. Copyright. 2009.

KOTLER, Philip. Administração de Marketing. São Paulo: Prentice Hall, 2000.

LATOUR, Bruno. Reagregando o social: uma introdução à teoria Ator-Rede. Salvador: Edufba, 2012. São Paulo: Edusc, 2012.

LEMOS, A. As estruturas antropológicas do ciberespaço. In: Cibercultura: tecnologia e vida social na cultura contemporânea. Porto Alegre: Sulina, 2008.

LOVELOCK, C.; WIRTZ, J. Marketing de serviços: pessoas, tecnologia e resultados. 5a ed. São Paulo: Pearson Prentice Hall, 2006.

MADDOX, Kates. Study: $\mathbf{8 6 \%}$ of B-to-B Marketers Now Use Content Marketing. AdvertisingAge, online, 2014. Disponível em: http://adage.com/article/digitalnext/ study-86-b-b-marketers-contentmarketing/295230/. Acesso em: 25/03/2017.

MATTOS, Alexandre. Marketing Digital: O que são Redes Sociais. 2009. Disponível em: <http://www.administradores.com.br/artigos/marketing_digital_o_que_ sao_redes_sociais_artigo_de_ale xandre_de_mattos_consultor_em_marketing_ digital/31442/>. Acesso em: 03/05/2017.

MORIGI, V. J; PAVAN, C. Tecnologias de informação e comunicação: novas sociabilidades nas bibliotecas universitárias. Ciência da Informação, Brasília, v. 33, n. 1, p. $117-125,2004$

Movimento de Protesto Ciberativista Interativo. VIII Simpósio Nacional da ABCiber. SP. 2014. 
O'BRIEN, B. H. L., \& TOMS, E. G. What is User Engagement? A Conceptual Framework for Defining User Engagement with Technology. Journal of the American Society for Information Science \& Technology, 59(6), pag. 938-955. 2008.

SECRETARIA DE COMUNICAÇÃO SOCIAL. Manual de orientação para atuação em mídias sociais. Versão 2.0. 2014. Disponível em: <http://www. secom.gov.br/pdfs-da-area-de-orientacoesgerais/internet-e-redes-sociais/ secommanualredessociaisout2012_pdf $>$. Acesso em: 02/04/2017.

VAN DOORN, J., LEMON, K. N., MITTAL, V., NASS, S., PICK, D., PIRNER, P., e VERHOEF, P. C. Customer Engagement Behavior: Theoretical Foundations and Research Directions. Journal of Service Research, Vol. 13, n.3, p. 253-266, 2010. 